\title{
INL HIP Plate Fabrication
}

B. H. Park

C. R. Clark

J. F. Jue

February 2010

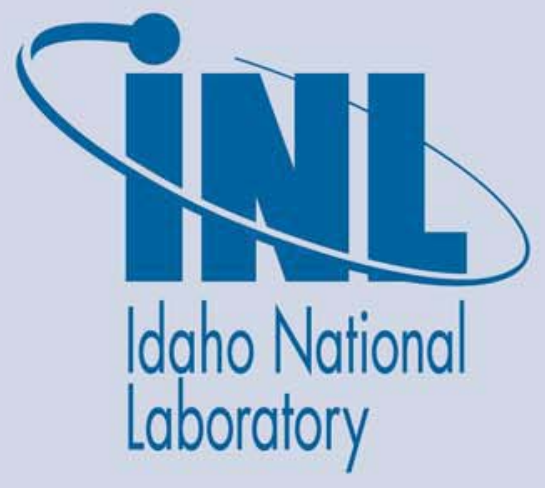

The INL is a U.S. Department of Energy National Laboratory operated by Battelle Energy Alliance 


\title{
INL HIP Plate Fabrication
}

\author{
B. H. Park \\ C. R. Clark \\ J. F. Jue
}

February 2010

\section{Idaho National Laboratory \\ Fuel Fabrication Development \\ Idaho Falls, Idaho 83415}

http://www.inl.gov

Prepared for the

U.S. Department of Energy

Office of National Nuclear Security Administration

Under DOE Idaho Operations Office

Contract DE-AC07-05ID14517 


\section{DISCLAIMER}

This information was prepared as an account of work sponsored by an agency of the U.S. Government. Neither the U.S. Government nor any agency thereof, nor any of their employees, makes any warranty, expressed or implied, or assumes any legal liability or responsibility for the accuracy, completeness, or usefulness, of any information, apparatus, product, or process disclosed, or represents that its use would not infringe privately owned rights. References herein to any specific commercial product, process, or service by trade name, trade mark, manufacturer, or otherwise, does not necessarily constitute or imply its endorsement, recommendation, or favoring by the U.S. Government or any agency thereof. The views and opinions of authors expressed herein do not necessarily state or reflect those of the U.S. Government or any agency thereof. 

Fuel Fabrication Development

INL HIP Plate Fabrication

INL/EXT-10-17792

February 2010 


\section{CONTENTS}

1. HOT ISOSTATIC PRESSING OF MONOLITHIC FUEL PLATES …...................................... 1

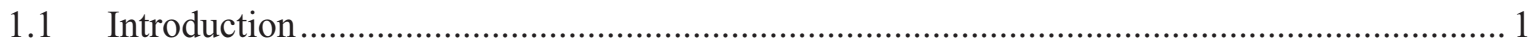

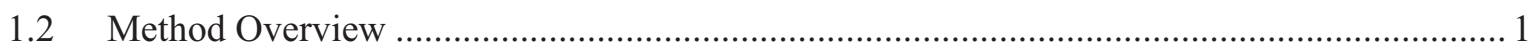

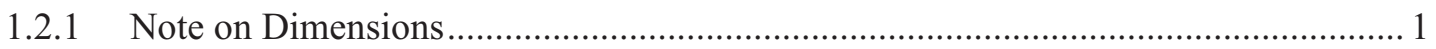

1.2.2 HIP Can Preparation ...................................................................................... 1

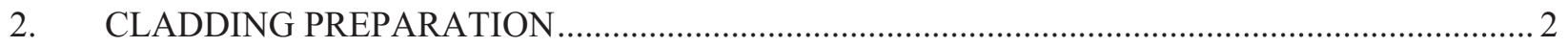

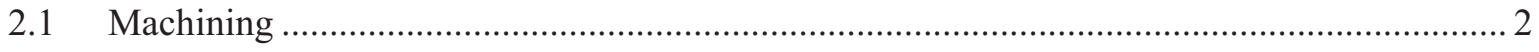

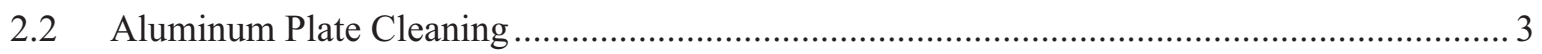

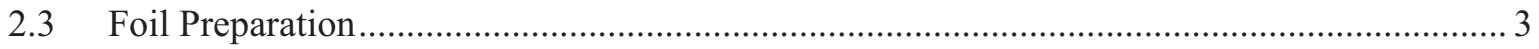

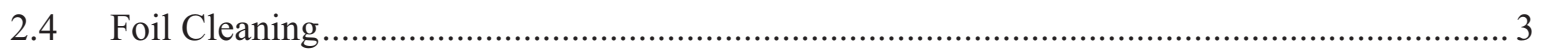

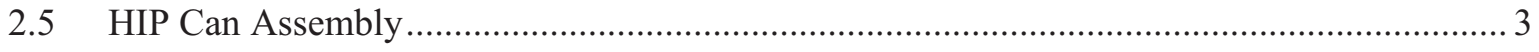

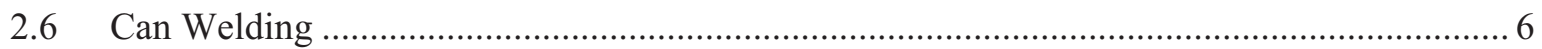

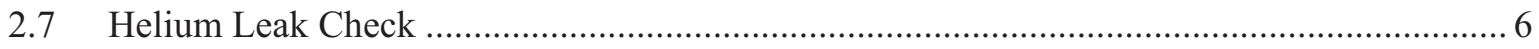

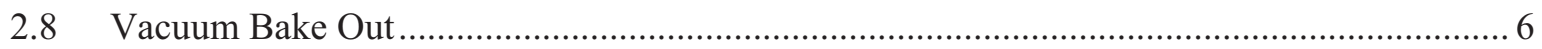

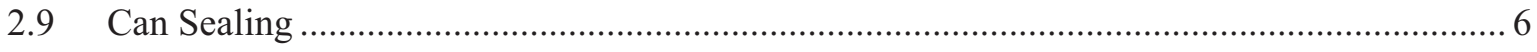

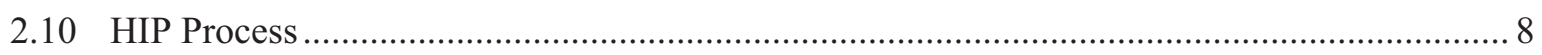

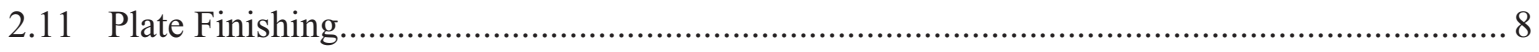

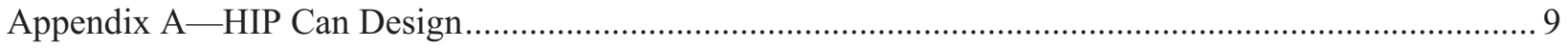

\section{FIGURES}

Figure 1. HIP can loading. Figure showing the HIP can during assembly. A partially assembled HIP can is lined with grafoil. Inside the HIP can is layered: grafoil, a strongback, a second sheet of grafoil, the aluminum plate (with a pocket machined in one face), and a foil.

Figure 2. Can crimping. 7

\section{TABLES}

Table 1. Grafoil requirements for miniplates HIP can....................................................................... 1

Table 2. Aluminum hardware thicknesses. ................................................................................... 2

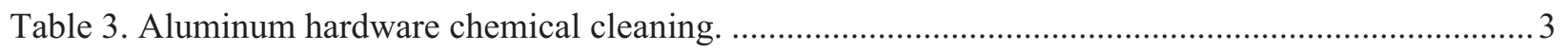

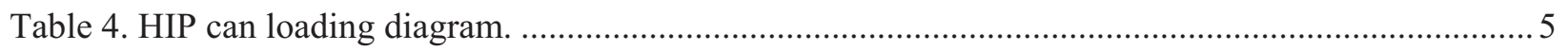

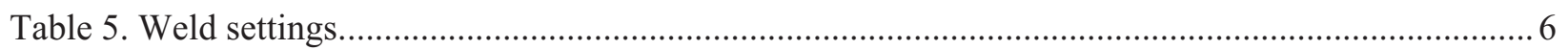

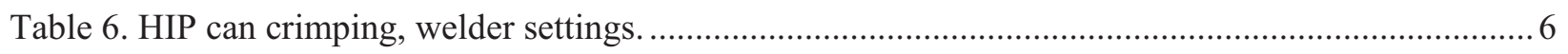

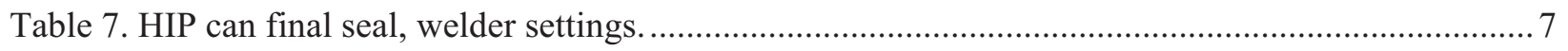

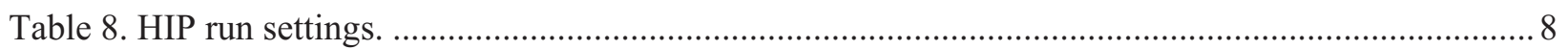




\section{INL HIP Plate Fabrication}

\section{HOT ISOSTATIC PRESSING OF MONOLITHIC FUEL PLATES}

\subsection{Introduction}

This document outlines the process used to bond monolithic fuel plates by Hot Isostatic Pressing (HIP). This method was developed at Idaho National Laboratory (INL) for the Reduced Enrichment for Research and Test Reactors (RERTR) program. These foils have been used in a number of irradiation experiments in support of the United States Global Threat Reduction Initiative (GTRI) program.

\subsection{Method Overview}

The U-10Mo (typical alloy) fuel meat will be supplied in the form of a "foil." This foil will be comprised of a U-Mo fuel meat bonded between two thin layers of zirconium that act as a protective barrier during the irradiation process. This foil is then sandwiched between two thin sheets of aluminum and placed in a steel can for HIP processing.

Prior to the HIP process, the can is heated under vacuum to remove contaminants through off-gassing and seal-welded under vacuum.

The HIP process is conducted in a commercial HIP at a temperature/pressure regime of $560^{\circ} \mathrm{C}$ for 90 minutes. Following cooling, the can is removed from the HIP, cut open, and the bonded plates are labeled and finished to the final dimensions.

\subsubsection{Note on Dimensions}

The process outlined here describes the fabrication of miniplates (measuring $1 \mathrm{in} . \times 4 \mathrm{in}$. with a fuel zone nominally 0.75 in. $\times 3.5$ in.). While the size disparity between miniplates and full size plates is great, the same basic methods and processes will remain the same.

\subsubsection{HIP Can Preparation}

The HIP can consists of 304 stainless steel (typical thickness 0.134 in.). Appendix A details the dimensions and plans. The can is preassembled with the exception that one cover plate and one side plate are left off to allow the plates to be assembled inside the can.

The partially assembled can, along with its unattached cover and side plates and its associated strongbacks, are stored in appropriate storage until needed (there is no time limit from initial assembly to final assembly.

Grafoil (Grade A 0.005 in thickness) is used as a separation media between the aluminum plates and the HIP can. The grafoil is cut with a sharp blade and should be handled with lint-free gloves. Foil sizes are shown in Table 1.

Table 1. Grafoil requirements for miniplates HIP can.

\begin{tabular}{|l|c|c|}
\hline \multicolumn{1}{|c|}{ Foil } & Dimensions (in.) & $\begin{array}{c}\text { Amount } \\
\text { Needed }\end{array}$ \\
\hline Strong Back Sized & $2.000 \times 5.875$ & 16 \\
\hline Top/bottom Plate Sized & $2.270 \times 3.030$ & $2^{\text {a }}$ \\
\hline Side Plate sized & $2.270 \times 5.905$ & 2 \\
\hline
\end{tabular}

a. The top plate foil has a hole of the size and location to match up with the tube attached to the top plate. 


\section{CLADDING PREPARATION}

\subsection{Machining}

The cladding for the plates is made of aluminum 6061 (independent chemical certification is typically required by the reactor). The aluminum is in two different pieces, a pocket plate that has a blind pocket machined to accept the foil and a flat cover plate. Both the cover and pocket plates are cut to be the same area ( 2 in. $\times 6$ in. for the miniplates).

The thickness of the plates varies with the fuel plate geometry. The thicknesses are varied to keep the foil centered in the final fuel plate. Table 2 provides examples for two common fuel foil thicknesses.

Table 2. Aluminum hardware thicknesses.

\begin{tabular}{|l|l|l|}
\hline \multicolumn{1}{|c|}{ Parameter } & \multicolumn{2}{c|}{ Size (in.) } \\
\hline Foil Thickness & 0.013 & 0.020 \\
\hline Final Plate Thickness & 0.055 & 0.055 \\
\hline Stackup Excess Thickness & 0.010 & 0.010 \\
\hline Cover Plate Thickness & 0.026 & 0.023 \\
\hline Pocket Plate Thickness & 0.039 & 0.043 \\
\hline Pocket Depth & 0.014 & 0.021 \\
\hline
\end{tabular}

Plate stock is procured from a commercial vendor. Various thicknesses are procured based on the geometry of the plates to be fabricated. Samples from each lot are sent to a certified vendor to be chemically analyzed (for compliance to ANSI standards for aluminum 6061).

The plates are cut to the required thickness by mounting the plates on a vacuum chuck and end milling to thickness. After the plates have been machined to thickness the plates are finished on each side by using the milling machine to wire brush the two surfaces. Tolerance on the thickness dimensions is \pm 0.001 in.

Following polishing, the pockets are cut into the pocket plates by end milling. The pockets are sized to fit the foil with a slight oversize to ensure that the plate will properly fit together during assembly. The pocket is oversized $0.020 \mathrm{in}$. in both the width and the length (tolerance on the pocket area is $\pm 0.005 \mathrm{in}$., and \pm 0.001 in. on the pocket depth).

The time from finishing to cleaning and assembly is minimal (typically within 2 days). 


\subsection{Aluminum Plate Cleaning}

The aluminum plates are chemically cleaned using standard methods. The schedule is found in Table 3 .

Table 3. Aluminum hardware chemical cleaning.

\begin{tabular}{|l|l|l|c|c|}
\hline \multicolumn{1}{|c|}{ Process } & \multicolumn{1}{|c|}{ Chemical } & \multicolumn{1}{|c|}{ Concentration } & $\begin{array}{c}\text { Temp } \\
\left({ }^{\circ} \mathrm{C}\right)\end{array}$ & $\begin{array}{c}\text { Time } \\
(\mathrm{sec})\end{array}$ \\
\hline Degrease & Acetone & Full & Ambient & N/A \\
\hline Degrease & Ethanol & Full & N/A & N/A \\
\hline Hot Etch & $\mathrm{NaOH}$ & $75 \mathrm{~g} /$ liter $\mathrm{H}_{2} \mathrm{O}$ & $80-85$ & 30 \\
\hline Water Rinse & $\mathrm{DI} \mathrm{H} \mathrm{H}_{2} \mathrm{O}$ & $\mathrm{NA}$ & Ambient & $\sim 10$ \\
\hline Wipe $($ Lint Free) & $\mathrm{NA}$ & $\mathrm{NA}$ & N/A & N/A \\
\hline Pickle & $\mathrm{HNO}_{3}$ & $30 \%$ in $\mathrm{H}_{2} \mathrm{O}$ & Ambient & 120 \\
\hline Water Rinse & $\mathrm{DI} \mathrm{H}_{2} \mathrm{O}$ & NA & Ambient & $\sim 10$ \\
\hline Hot Rinse-I & $\mathrm{DI} \mathrm{H}_{2} \mathrm{O}$ & NA & $80-85$ & $\sim 15$ \\
\hline Hot Rinse-II & DI $\mathrm{H}_{2} \mathrm{O}$ & NA & $80-85$ & $\sim 15$ \\
\hline Wipe $($ Lint Free) & N/A & N/A & N/A & N/A \\
\hline
\end{tabular}

After cleaning, the plates are to be used for can assembly within 1 hour or stored under partial vacuum (wrapped in lint-free cloths) to maintain cleanliness.

\subsection{Foil Preparation}

Foils are to be tracked to maintain positive identification (ID) and to meet all applicable nuclear material tracking requirements.

\subsection{Foil Cleaning}

The foils are cleaned by immersing in a $\sim 30 \%$ nitric acid (in water) solution. The fuel foil will turn a light brown in the solution (the time will vary based on the amount of corrosion on the beginning foil). Following the nitric bath, the foils are rinsed in deionized water to dilute the nitric acid. The brown tarnish is then removed by placing the foil on a flat, stable surface (e.g., a metal plate) and is ground with coarse (typically 80 grit) emery cloth. The cloth is kept damp and is changed as needed during cleaning. After the brown deposit is removed, the plate is wiped with a dry cloth and then wiped again with a cloth dampened with ethanol. If the foil proves to be difficult to clean, the nitric acid bath process may be repeated.

\subsection{HIP Can Assembly}

Can assembly is to take place in a clean area removed from distractions and other work that may interfere with the process.

The HIP can and all other metal parts (strongbacks) are to be cleaned with acetone and ethanol wipes just prior to assembly. Following the wipedown parts are to be handled only with lint-free gloves. 
Using a supplied can loading diagram (Table 4) the can is to be properly oriented on the work surface. This orientation is vital as it serves as the primary indicator for plate identification. The can is lined with grafoil and the contents of the can are stacked per the diagram. As the loading proceeds, care is to be taken to identify each part as it is loaded into the assembly. As the foils are loaded ensure each is properly seated and that it remains in the machined pocket (Figure 1).

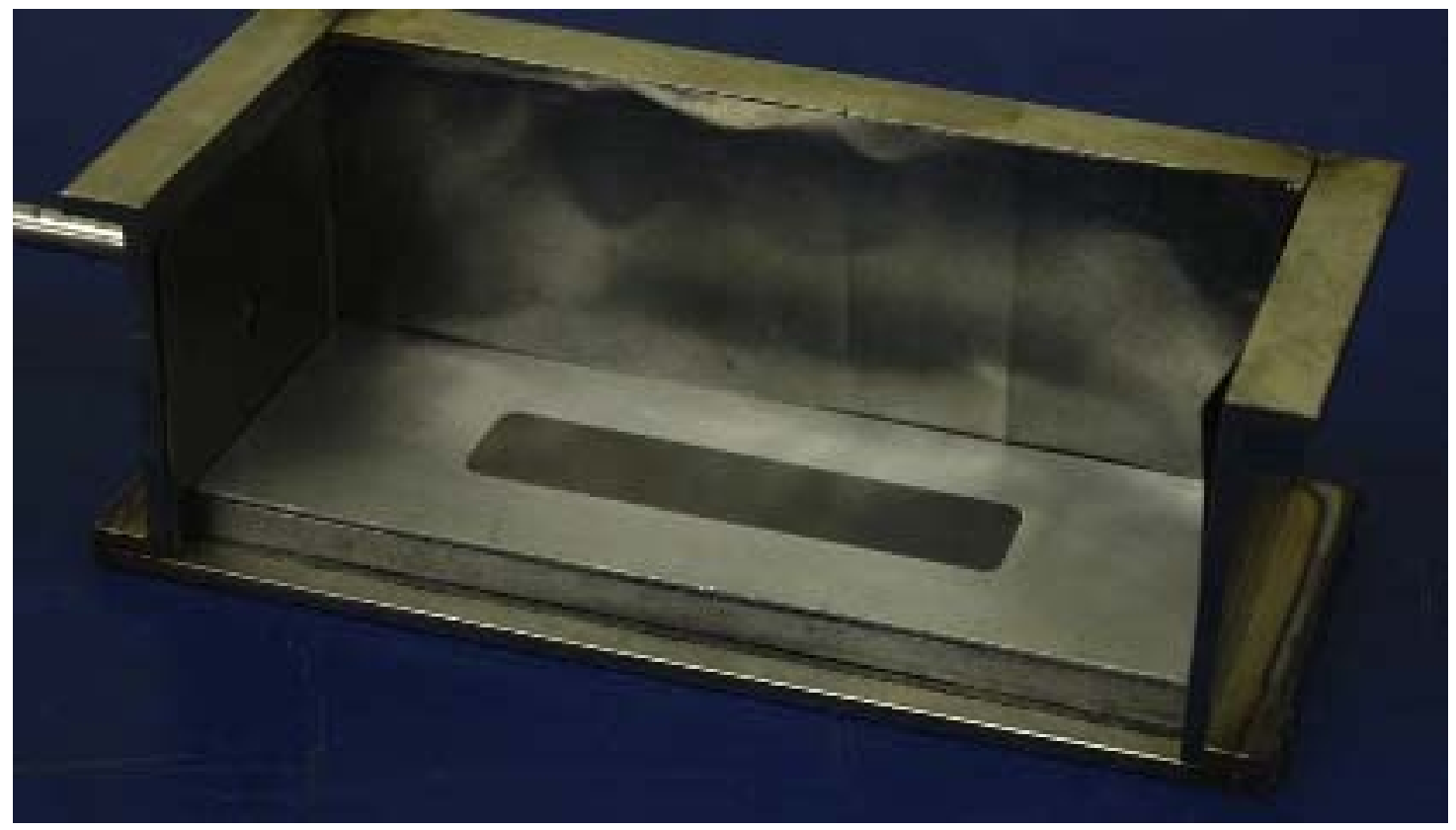

Figure 1. HIP can loading.

After the stacking is finished, position the missing side and top plate on the can assembly. Secure these in place with C-clamps (or similar). Extreme care should be taken when handling the assembled can to avoid dislodging the foil from the aluminum pocket. 
Table 4. HIP can loading diagram.

\begin{tabular}{|c|c|c|c|}
\hline Plate & Item & Foil ID & Check \\
\hline- & Grafoil & - & $\square$ \\
\hline- & Strongback & - & $\square$ \\
\hline- & Grafoil & - & $\square$ \\
\hline \multirow{3}{*}{6} & 6061 Cover plate & - & $\square$ \\
\hline & Fuel foil & [Foil 6 ID] & $\square$ \\
\hline & 6061 Pocket Plate & - & $\square$ \\
\hline- & Grafoil & - & $\square$ \\
\hline- & Strongback & - & $\square$ \\
\hline- & Grafoil & - & $\square$ \\
\hline \multirow{3}{*}{5} & 6061 Cover plate & - & $\square$ \\
\hline & Fuel foil & [Foil 5 ID] & $\square$ \\
\hline & 6061 Pocket Plate & - & $\square$ \\
\hline- & Grafoil & - & $\square$ \\
\hline- & Strongback & - & $\square$ \\
\hline- & Grafoil & - & $\square$ \\
\hline \multirow{3}{*}{4} & 6061 Cover plate & - & $\square$ \\
\hline & Fuel foil & [Foil 4 ID] & $\square$ \\
\hline & 6061 Pocket Plate & - & $\square$ \\
\hline- & Grafoil & - & $\square$ \\
\hline - & Strongback & - & $\square$ \\
\hline - & Grafoil & - & $\square$ \\
\hline \multirow{3}{*}{3} & 6061 Cover plate & & $\square$ \\
\hline & Fuel foil & [Foil 3 ID] & $\square$ \\
\hline & 6061 Pocket Plate & - & $\square$ \\
\hline- & Grafoil & - & $\square$ \\
\hline - & Strongback & - & $\square$ \\
\hline- & Grafoil & - & $\square$ \\
\hline \multirow{3}{*}{2} & 6061 Cover plate & - & $\square$ \\
\hline & Fuel foil & [Foil 2 ID] & $\square$ \\
\hline & 6061 Pocket Plate & - & $\square$ \\
\hline- & Grafoil & - & $\square$ \\
\hline- & Strongback & - & $\square$ \\
\hline- & Grafoil & - & $\square$ \\
\hline \multirow{3}{*}{1} & 6061 Cover plate & - & $\square$ \\
\hline & Fuel foil & [Foil 1 ID] & $\square$ \\
\hline & 6061 Pocket Plate & - & $\square$ \\
\hline - & Grafoil & - & $\square$ \\
\hline- & Strongback & - & $\square$ \\
\hline- & Grafoil & - & $\square$ \\
\hline
\end{tabular}




\subsection{Can Welding}

Welding the assembled can takes place in a purified argon glovebox (with $\mathrm{O}_{2}$ concentration typically $<10 \mathrm{ppm}$ ). A tungsten inert gas (TIG) welding setup is employed (despite the inert glovebox, argon cover gas is used during welding - primarily to cool the weld). Weld settings are given in Table 5.

Table 5. Weld settings.

\begin{tabular}{|c|c|c|}
\hline AC/DC & Amperage & Start \\
\hline DC & 125 & LiftArc $^{\mathrm{a}}$ \\
\hline $\begin{array}{l}\text { a. LiftArc is an arc starting process on Miller welding power } \\
\text { supplies; high frequency start is not used here due to the } \\
\text { proximity to the glovebox control units }\end{array}$ \\
\hline
\end{tabular}

The can is moved into a suitable location allowing the welder access to the work area and the loose parts of the can (top and side) are tack welded to the rest of the can. The clamps are then removed. The unwelded, joined edges are then welded using weld wire (3/32 in. 308 stainless or similar). Following the welding (and any cooldown to allow handling) the welds are visually inspected for any flaws, the welds are redone as needed.

\subsection{Helium Leak Check}

A commercial leak checking unit is used to test the integrity of the welded joints. The tube of the HIP can is connected to the inlet of the leak check unit (compression fitting) and the can is placed inside a poly bag that is taped shut, while allowing the tube to remain connected. Helium is introduced into the bag surrounding the HIP can and the setup is allowed to reach a steady state. Rejection criteria for the He leak check is $1 \times 10^{7} \mathrm{cc} / \mathrm{sec}$. If a leak is found the specific site is identified by a more selective sniffing technique. The HIP can may be rewelded as required.

\subsection{Vacuum Bake Out}

The leak-checked HIP can is connected to a mechanical vacuum pump via the compression fitting on the tube. The can is then placed in a furnace and the opening is packed with insulation (the door remains open to allow the vacuum to remain attached to the can) to provide a thermal barrier at the furnace boundary.

The can is heated to $315^{\circ} \mathrm{C}$ and held for 3 hours under vacuum. Following the 3 hours, the can (still under vacuum) is removed from the furnace and allowed to cool to nearly room temperature.

\subsection{Can Sealing}

To seal the HIP can tube it is heated and crimped in several (typically four or five) locations. The heating is performed by passing current through the HIP can (the tube being a much less massive cross section than the bulk of the can will experience the vast majority of the resistance heating). The electrical leads are attached to the end of the tube and to the body of the HIP can. The welding unit is set per Table 6.

Table 6. HIP can crimping, welder settings.

\begin{tabular}{|c|c|c|}
\hline $\mathrm{AC} / \mathrm{DC}$ & Amperage & Start \\
\hline $\mathrm{DC}$ & 250 & Stick \\
\hline
\end{tabular}


The welding unit is energized and as the tube turns cherry red (approximately $900^{\circ} \mathrm{C}$ ) (Figure $2 \mathrm{a}$ ) the current is adjusted as needed by an operator to maintain this condition. While the stem is heated, a hydraulic crimper is applied in several places along the tube (Figure 2b). After the crimping the can is allowed to cool to a temperature where it can be handled using gloves.

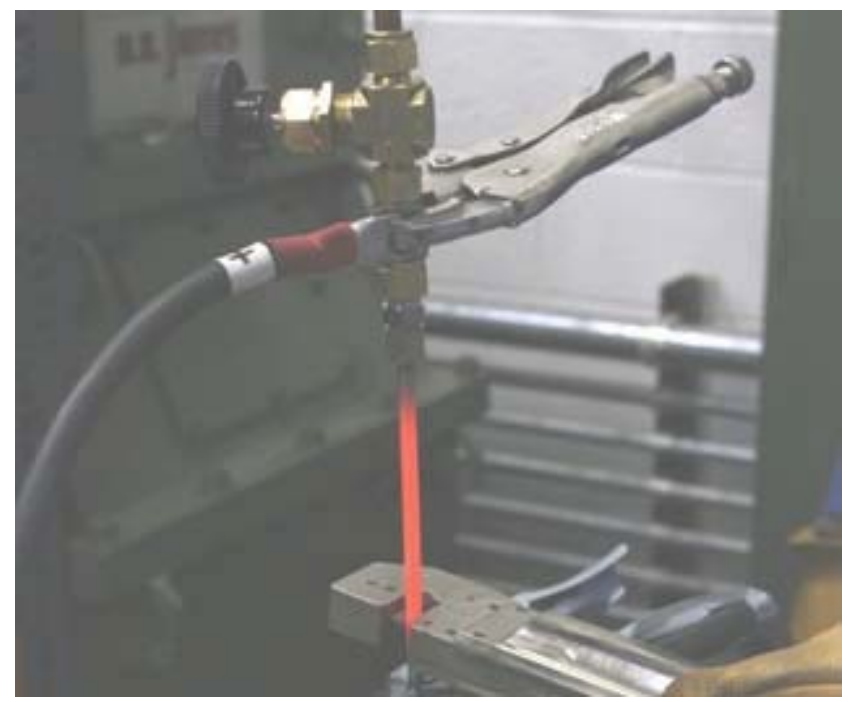

(a)

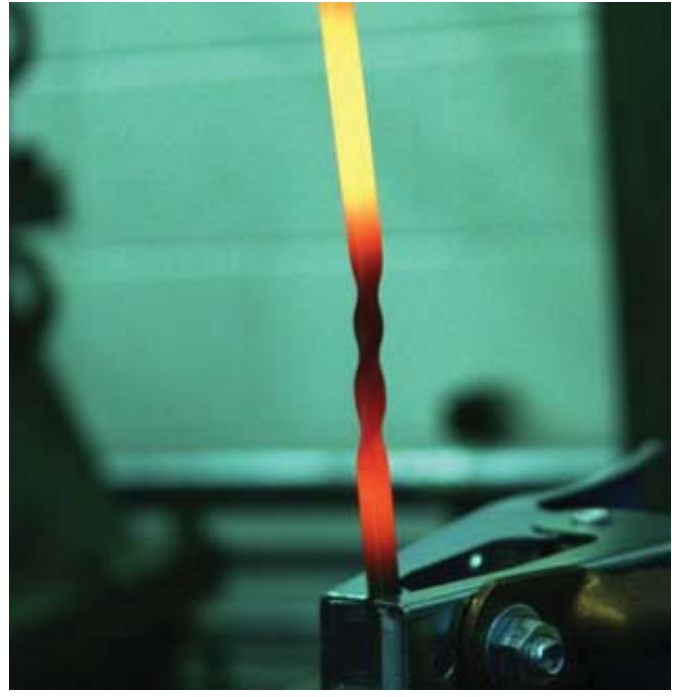

(b)

Figure 2. Can crimping.

The welding unit is setup for the final closure weld with the settings given in Table 7.

Table 7. HIP can final seal, welder settings.

\begin{tabular}{|c|c|c|}
\hline AC/DC & Amperage & Start \\
\hline DC & 25 & High Frequency \\
\hline
\end{tabular}

The tube is broken at the uppermost crimp (farthest from the HIP can) by bending the top of the tube back and forth, while supporting the tube immediately below the top crimp, until the tube fractures (via low-cycle fatigue). The exposed end of the tube is quickly welded using the above settings. The end of the tube is visually examined under a magnifying glass for any flaws. If needed, the weld can be repaired or repeated by breaking the next crimp point along the tube length.

Following the can closure, a base is welded onto the bottom of the HIP can. This is to provide greater stability for the can during the HIP run and help centrally locate the can in the hot zone. The base dimensions are dependent on the geometries of both the HIP can and the HIP itself. It is tack welded in place using the settings from Table 5 above. 


\subsection{HIP Process}

The can is loaded into the HIP according to the operating manual and best practices for the local unit. The HIP run is then conducted per Table 8.

Table 8. HIP run settings.

\begin{tabular}{|c|l|l|l|l|l|}
\hline Step & \multicolumn{1}{|c|}{ Action } & \multicolumn{1}{c|}{ Rate } & \multicolumn{1}{c|}{ Time } & \multicolumn{1}{c|}{ Temperature } & \multicolumn{1}{c|}{ Pressure } \\
\hline 1 & Ramp Up & $280^{\circ} \mathrm{C} / \mathrm{hr}$ & $\sim 60 \mathrm{~min}$ & To $320^{\circ} \mathrm{C}$ & 1000 psi initial setting \\
\hline 2 & Ramp Up & $280^{\circ} \mathrm{C} / \mathrm{hr}$ & $\sim 60 \mathrm{~min}$ & To $560^{\circ} \mathrm{C}$ & Quasi controlled to $15,000 \mathrm{psi}$ \\
\hline 3 & Hold & N/A & $90 \mathrm{~min}$ & $560^{\circ} \mathrm{C}$ & 15,000 psi \\
\hline 4 & Ramp Down & $280^{\circ} \mathrm{C} / \mathrm{hr}$ & $\sim 35 \mathrm{~min}$ & To $\sim 400^{\circ} \mathrm{C}$ & Not controlled \\
\hline 5 & Ramp Down & $280^{\circ} \mathrm{C} / \mathrm{hr}$ & $\sim 85 \mathrm{~min}$ & To $\sim 20^{\circ} \mathrm{C}$ & Quasi controlled \\
\hline
\end{tabular}

Following cool down, the HIP can is unloaded. The success of the HIP run can be tentatively gauged by the appearance of the can. Bulging of the can in any area is indicative of a failed HIP run.

The HIP can is removed by cutting open the can using a band saw (the HIP can is designed to have a clear cutting path where the welds can be removed without the necessity of cutting through the body of the can-see Appendix A).

As the plates are removed it is vital to establish a positive identification, which is typically done through orientation inside the can. The plates are stamped with the ID number (a surface relief markings system is desirable as it shows a positive ID [and locator] on the ultrasonic test (UT) scan).

\subsection{Plate Finishing}

The plates are finished both to obtain a final thickness and a suitable surface finish. Typically, this is done in two steps: initial polishing that allows an initial UT scan and finishing to a final thickness. The UT scan locates the fuel foil inside the plate and identifies any areas where the final thickness reduction may run into problems (i.e., regions where the fuel foil may be closer to the surface). Initial polishing is done with a milling machine using a vacuum chuck and an end mill.

Following the initial finishing and the UT scan the plates are finished to final thickness using the same setup as before. During machining, one face or another may be preferentially cut, as needed, as indicated by the results of the UT scan. 
Appendix A

\section{HIP Can Design}




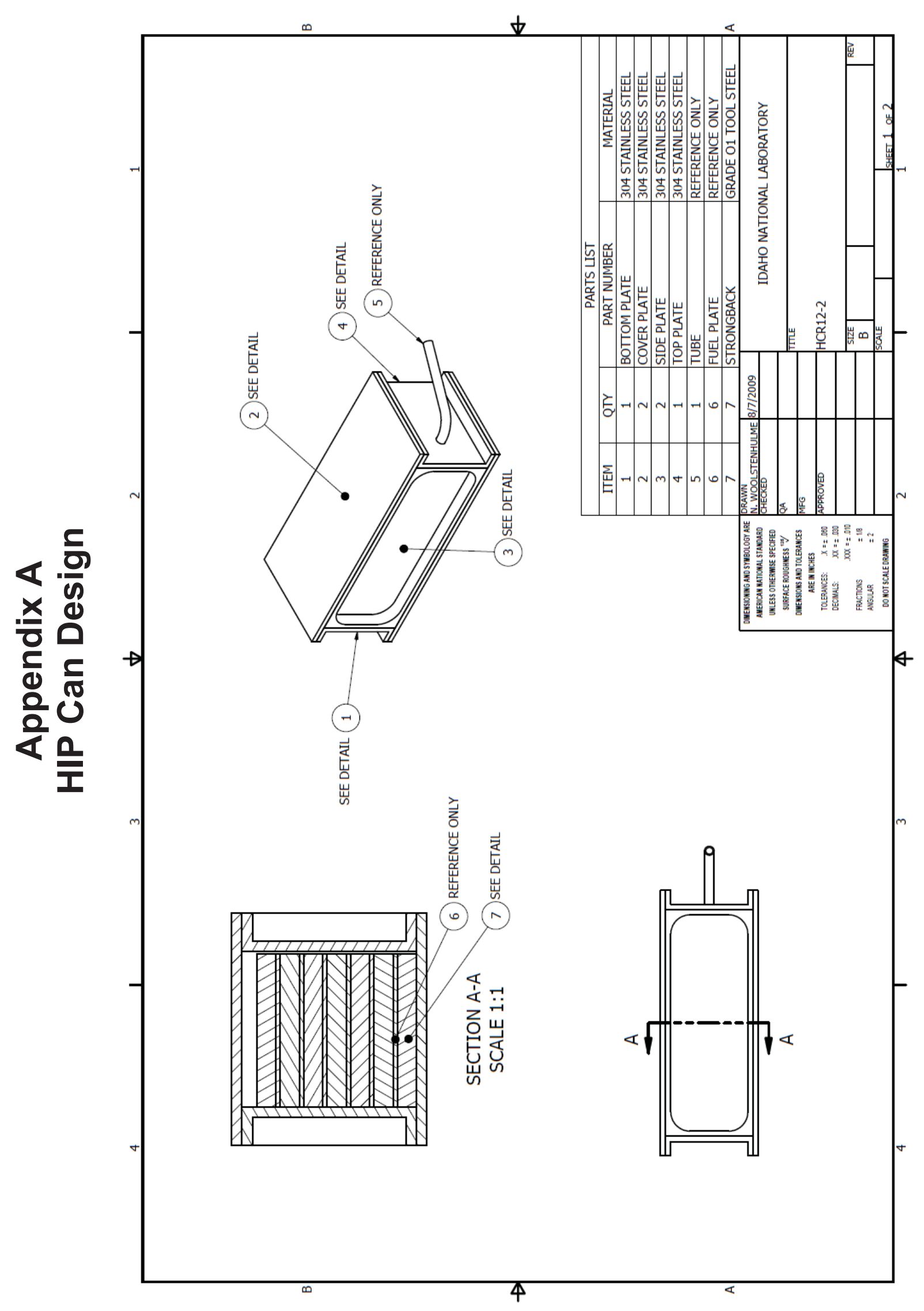




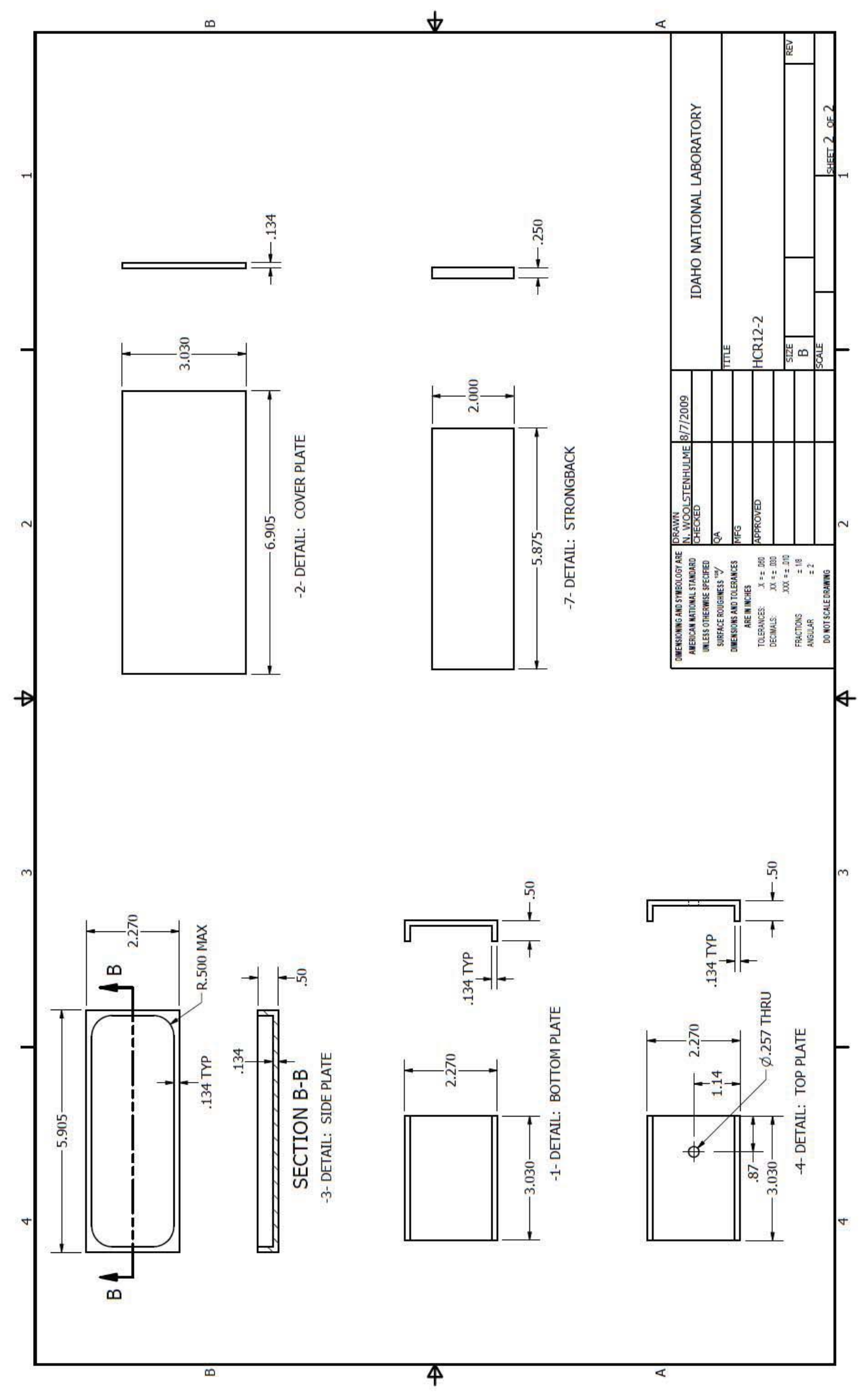

